\title{
Después de la muerte: Procesos de transformación social y política en la Argentina reciente
}

\author{
After death: Processes of social and political \\ transformations in recent Argentina
}

GAYOL, Sandra y KESSLER Gabriel. Muertes que importan. Una mirada sociohistórica sobre los casos que marcaron la Argentina reciente. Buenos Aires: Siglo XXI, 2018. 264p.

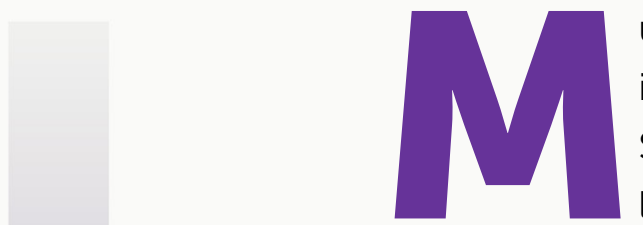

uertes que importan trata, a partir de un trabajo interdisciplinario que involucra a una historiadora, Sandra Gayol, y a un sociólogo, Gabriel Kessler, la relación entre muertes violentas, problemas públicos y cambios en la Argentina reciente (1985-2002). El punto de partida son múltiples muertes evitables de personas indefensas, de los sectores medios y populares, a manos de individuos o grupos de individuos vinculados con el poder, especialmente estatal. La pregunta que articula toda la reflexión es: ¿qué tiene que tener una muerte para que sea política y socialmente significativa? Es decir, que sea capaz de conmover a una parte amplia de la sociedad e interpelar a los poderes públicos. ¿Por qué muertes similares, muy semejantes, no producen las mismas reacciones? Son las muertes que logran gran conmoción social y eficacia política las que lideran el trabajo y las que son transformadas por los autores, de manera muy original, en casos que, como herramienta heurística, permite conocer una dimensión del problema general que

* Profesorado Universitario de Educación Superior en Historia, Prepara su Doctorado en Ciencias Sociales, Universidad Nacional de General Sarmiento (UNGS)-IDES. Cv: https://www.conicet.gov.ar/ new scp/detalle.php?id=52210\&datos academicos=yes 
cada muerte encarna. La violencia estatal está en el centro de la escena y con cada homicidio perpetrado se moldeará un problema público particular. Cada caso analizado, entonces, contribuirá a configurar, impulsar o generar un tema que en determinado momento y gracias a la intervención de distintos actores, se transforma en motivo de preocupación o enojo para la sociedad ¿Por qué fueron o son importantes estas muertes? Aquí radica el argumento principal: una muerte que podría no haber traspasado el límite del ámbito privado se visibiliza en el espacio público a partir de una combinación virtuosa de diferentes factores: la violencia pre y post-mortem sobre los cuerpos de las víctimas, el involucramiento de diferentes actores con la muerte que se traduce en movilizaciones y pedidos de esclarecimiento y de justicia, la coyuntura política en la que se inserta, la capacidad de esa muerte particular de actualizar muertes anteriores, de hacer serie con muertes semejantes que en general no habían concitado previamente interés y condena social, y su presencia duradera en tanto noticia en los medios masivos de comunicación. Los autores se valen de un rico corpus documental que incluye los diarios de mayor tirada nacional, periódicos locales, revistas nacionales, programas televisivos y radiales, debates parlamentarios, leyes y decretos, libros de investigación, obras de ficción y representaciones estéticas diversas y una cantidad notable de entrevistas. El libro está organizado en una introducción, que expone los argumentos principales y la estrategia metodológica, cinco capítulos que despliegan de forma correlativa el análisis y los argumentos presentados en la introducción y una conclusión en donde se retoman los principales argumentos y se sugieren líneas posibles de investigación futura.

Los gobiernos que se suceden a partir de la restauración democrática de 1983, organizan temporal y analíticamente el primer capítulo, "Un mapa de muertes visibles", el cual ofrece un paneo de muertes que tuvieron trascendencia pública. Estas se ordenan en fases políticas que se superponen y, además de mostrar la omnipresencia de la muerte en el discurso público, sugieren la preeminencia en la preocupación social de un tipo de muerte por sobre otra en cada una de las fases. Estas se inician con el gobierno de Raúl Alfonsín (1983-1989), continúa con las presidencias de Carlos Menem (1989- 1995 y 1995-1999), prosigue con la de Fernando de la Rúa (1999-2001) y culmina con los primeros años de la presidencia de Néstor Kirchner. El segundo capítulo, "Morir en papel y en pantalla", se centra en el tratamiento que los medios de comunicación impresos de alcance nacional hicieron de asesinatos que, sostienen los autores, plantearon problemas públicos y contribuyeron significativamente a modelar la política y la sociedad argentina de la última post-dictadura. La mira está puesta, como en los dos capítulos posteriores, en cinco casos que se nacionalizaron: el del banquero Osvaldo Sivak secuestrado en la ciudad de Buenos Aires en 1985 y encontrado muerto en 1987; el asesinato en 1987, por la policía, de tres jóvenes mientras bebían pacíficamente cerveza en la puerta de un bar en el barrio popular de la localidad de Ingeniero Budge en la provincia de Buenos Aires; la violación y asesinato de María Soledad Morales en la ciudad de Catamarca en 1990; el asesinato del joven Omar Carrasco en el cuartel de Zapala, provincia de Río Negro, en 1994; y el de Maximiliano Kosteki y Darío Santillán en la ciudad de Avellaneda en junio de 2002. En el caso Sivak, el análisis se detiene en la coordinación entre periodistas y familiares de la víctima, puntualmente en su esposa. Para Ingeniero Budge, caso que inauguró el proceso 
de construcción de la categoría de "gatillo fácil", el interés se recorta en la protesta vecinal, la "simpatía" de los medios de comunicación con ella, y las versiones o relatos alternativos a la verdad oficial de la institución policial acerca de las causas de las muertes. Por otro lado, en el caso de María Soledad Morales, la atención se fija en la coordinación y legitimación recíprocas entre medios locales y nacionales. El caso Carrasco es interesante debido a los modos y razones a través de los cuales se construyó la divergencia mediática respecto a las opiniones sobre la utilidad, legitimidad y continuidad o fin del Servicio Militar Obligatorio (SMO). El asesinato de los militantes políticos Maximiliano Kosteki y Dario Santillán en junio de 2002, a manos de la policía, en el contexto de protestas generalizadas como consecuencia de una crisis económica, se constituye aquí como un caso que deja entrever el poder de las imágenes. Las fotos del periódico Página 12 evidenciaban por sí mismas que Darío Santillán estaba aún con vida antes de que la policía llegara al lugar en el que se encontraba, lo cual contradecía la versión oficial, que atribuía las muertes a la violencia de la protesta. Las imágenes permitieron, así, hablar de violencia policial, lo cual generó un efecto político y la reacción social. A partir de una muerte particular el lector puede entrever tanto el proceso de construcción de la noticiabilidad como las transformaciones en los medios de comunicación que inciden en los modos de contar la muerte.

El cuerpo, su materialidad, su poder simbólico, protagoniza el capítulo tres, "Cuerpos sin tregua". Tanto la conmoción, la protesta social y los cambios posteriores que estimula o inicia un asesinato pueden comenzar a ser explicados por un cuerpo violentado y ultrajado, en vida y post-mortem. La forma en que fueron maltratadas y asesinadas las víctimas genera la indignación social inicial y el inicio de un complejo camino de demanda al Estado por el esclarecimiento y la reparación de estas muertes. Cada caso parece provocar la sensación de que se ha ido demasiado lejos y el ultraje individual se torna colectivo. Los cuerpos muertos deben pugnar con toda una serie de chismes, rumores y versiones -sutilmente analizados por los autores- para imponerse como víctimas inocentes. La condición de víctima es un proceso y como tal requiere el trabajo de familiares, amigos y activistas. Son estos quienes emprenden la construcción de la biografía post-mortem para posibilitar el proceso de victimización. El capítulo cuatro, "Las huellas del cambio", nos sugiere que muchas muertes fueron generadoras de cambios. Estos ocurrieron, según los autores, tanto a nivel de las instituciones, en la práctica política y la cultura política, así como en la conformación de organizaciones y en el impacto en las subjetividades. Se pone en juego un interesante análisis que contempla dos dimensiones: la de los contemporáneos a los eventos - las entrevistas realizadas resultaron nodales- y aquella correspondiente a la reconstrucción analítica, minuciosa y sutil, de la relación entre una muerte y el cambio que se le atribuye. Como muestra claramente el capítulo, ambas dimensiones no coinciden. En la memoria social la relación es directa, mientras que en el análisis diacrónico todo es mucho más complejo. Los cambios son imprevisibles y, más importante, no devienen de un proceso acumulativo inscripto en el origen del evento. Si se analizan los discursos y la participación de diversos actores en ellos, las mutaciones no parecían evidentes. Las rupturas portan múltiples dimensiones y son multicausales, en ocasiones ni siquiera previstas por los principales actores involucrados. Acción y contingencia se imponen en el análisis. El capítulo 
cinco, "A escala local", oficia de contra-espejo de los anteriores en la medida que incursiona en asesinatos social y políticamente significativos para los espacios locales en donde acontecieron pero que no se nacionalizaron. No se nacionalizaron en un doble sentido: los medios de comunicación con cobertura nacional no las invocan de modo sistemático y recurrente y, ni la opinión pública ni los discursos y acciones de los agentes del gobierno central se las apropian como representativas de un problema de toda la sociedad argentina. La intención de este capítulo es tanto temática como metodológica: el objetivo es observar en qué punto las escalas, tanto local como nacional, pueden involucrarse entre sí e interactuar y, al mismo tiempo, mostrar la productividad analítica e interpretativa de este tipo de aproximaciones. Este "juego de escalas" muestra que la muerte se juega en todos los niveles de análisis, por supuesto, pero no lo hace de la misma manera. La repercusión en el espacio local se da en la intersección entre lugar y clase: una muerte en el centro de una ciudad impacta sea quien sea la víctima, aunque quizás más si se trata de una familia conocida. Pero, si esa muerte tiene lugar en la periferia o en áreas rurales, y no entre los estratos medios o altos del lugar, esa muerte pareciera impactar mucho menos. Todas las muertes buscan ser explicadas, ordenadas. Se busca que ingresen en un sistema de clasificación que al mismo tiempo que las integra les quita especificidad. Pero también hay muertes violentas que no despiertan ni la pena ni el llanto social. Importan no por sí mismas sino porque vienen a reforzar lo que ya se sabe: la peligrosidad -en ocasiones del propio muerto- del espacio para el entorno y los habitantes que están próximos. Ciertos atributos del espacio social, su historia y la imagen que se fue construyendo sobre él confluyen para otorgar a sus muertes locales menor repercusión o condena que si hubieran sucedido en otros espacios. Como un lugar peligroso y delictivo, a sus muertos se les niega inocencia: no son víctimas. El juego de escalas entre el plano local y el espacio público nacional puede mostrar cómo esta estigmatización territorial puede generar en un espacio local se construya una relación con la muerte diferente que la analizada en otros casos.

El libro termina con una conclusión que sostiene que no todas las muertes se configuraron de igual manera como problema público; cada una de ellas desarrolló un derrotero particular, contingente. Algunas establecieron serie con casos anteriores y otras no; algunas configuraron un problema nuevo y otras contribuyeron a reflotar otro preexistente. Muertes que importan nos enseña también que la relación que mantienen las personas con la muerte se modifica muy rápidamente, en todo caso a un ritmo más rápido que lo afirmado por la historiografía, y que, en Argentina, tanto la última dictadura como los gobiernos democráticos que le sucedieron resultaron claves a la hora de redefinir las relaciones de las mujeres y los hombres con la muerte. Los casos mencionados en el libro interpelaron y afectaron al Estado, lo cuestionaron, y buscaron poner límite a la capacidad de hacer morir estatal. Especialmente con la "restauración democrática" se va consolidando públicamente la idea de que la vida del otro importa, de que existen derechos referidos a la vida y a la muerte de los ciudadanos y límites a la necropolítica.

Muertes que importan es un libro novedoso, interesante y complejo, que coloca a la muerte en el centro de un análisis minucioso que se efectúa con diferentes lentes, y se 
presenta definitivamente como una propuesta original de contar la historia argentina reciente, sus transformaciones y continuidades, a partir de un aparente fin, como lo es la muerte.

Recibido en: 30 de noviembre

Aprobado en: 02 de diciembre 